\title{
A arbitragem no âmbito da Alca e outros apontamentos legais referentes ao tema
}

\author{
DURVAL DE N ORONHA GOYOSJR.
}

\section{Introdução}

A I I I I ATIVA da Área de Livre Comércio das Américas (Alca) foi concebida pelos Estados U nidos da América (EU A) e formatada no Acordo de Livre Comércio da A mérica do $\mathrm{N}$ orte $(\mathrm{N} \text { afta })^{1}$, pacto que trouxe enormes vantagen s comerciais aos agentes comerciais, industriais e agrícolas dosEU $A$, bem como uma extraordinária dependência econômica, financeira e política do M éxico àquele país ${ }^{2}$. D e fato, após a assinatura do $\mathrm{N}$ afta, as exportações estadunidenses para o M éxico cresceram $50 \%$ e o volume de comércio externo mexicano com os EU A aumentou de 72\%, em 1994, para aproximadamente $91 \%$, nos dias de hoje. Provedores estadunidenses dominaram o mercado de serviços mexicano, inclusive no setor financeiro, que foi quase que totalmente desnacionalizado. As barreiras horizontais existentes e mantidas nos EU A para os prestadores de serviços mexicanos, sujeitos a cotas, impediram uma escala internacional para estes, que sucumbiram à competição desigual e predatória .

N o setor agrícola, os mexicanos, que não negociaram no âmbito do $\mathrm{N}$ afta a eliminação das escandalosas políticas de subsídios mantidas pelos EU A, perderam sua competitividade para os produtos subsidiados baratos vindos deste país, tendo sofrido grandes perdas setoriais internas, a ponto de hoje tentarem renegociar a questão tardiamente, incluindo até mesmo certos "mecanismos de defesa" ${ }^{4}$. N a área industrial, o M éxico teve de aderir à perversa equação de que, quanto mais pobre sua população, mais competitivos serão seus produtos industrializados, especializando-se na manufatura de itens de baixo valor agregado. Como resultado, os salários industriais mexicanos tiveram uma redução expressiva e o país tornou-se um exportador de miséria ${ }^{5}$, tanto na forma de produtos maquilados, como na triste emigração econômica.

As conseqüências projetadas dos prováveis efeitos nefastos da Alca, em todos os setores indicados acima, têm sido objeto de muitas excelentes análises elaboradas no Brasil ${ }^{6}$ e algumas na Argentina ${ }^{7}$. Todavia, muito pouco se tem escrito sobre os aspectos legais inerentes à iniciativa e suas possíveis repercussões para o nosso país. É este o objeto do presente trabalho, que se divide, a partir daqui, da seguinte forma: a hierarquia dos tratados internacionais face à lei do- 
méstica dos EU A; a natureza ilícita da oferta discriminatória dos EU A no âmbito da Alca; 0 anacrônico sistema de arbitragem proposto para a Alca; e C onclusões.

\section{A hierarquia dos tratados internacionais face à lei doméstica dos E U A}

A Convenção de Viena sobre a Lei dos Tratados ${ }^{8}$ (Convenção de Viena) procurou codificar o direito internacional costumeiro reconhecido, bem como promover desenvolvimentos necessários na área, enfatizando matérias relevantes como conclusão, entrada em vigor, cumprimento, reservas, interpretação, exeqüibilidade, término e suspensão de tratados. O s dispositivos da Convenção de Viena são mandatórios apenas para as respectivas partes signatárias. C ontudo, como muitos destes seus dispositivos representam nada mais do que o reconhecimento do direito internacional costumeiro, estes são aplicáveis a todos os E stados e tratados internacionais. M esmo aqueles dispositivos da Convenção de Viena que não são a expressão normativa do direito costumeiro devem ser interpretados como presunção de direito internacional costumeiro em formação, para casos de países não signatários daquele tratado ${ }^{9}$.

Dentre as normas da Convenção de Viena de particular relevância para pactos internacionais de comércio, encontram-se os dispositivos pertinentes às reservas aos tratados internacionais, matéria que não representava prática universal quando de sua adoção. Assim, o artigo 19 da Convenção de V iena permite a reserva a dispositivos de acordos internacionais, a menos que:

i) a reserva seja proibida pelo tratado;

ii) o tratado estabeleça que somente outras reservas especificadas possam ser formuladas; ou

iii) a reserva seja incompatível com o objeto do tratado.

D a mesma forma, o artigo 26 da Convenção de Viena consagra a regra pacta sunt servanda na lei dos tratados e o princípio da boa fé nos acordos internacionais. Por sua vez, o artigo 27 do mesmo tratado determina que um Estado soberano não pode invocar seu direito interno como uma justificativa legal para inadimplir uma obrigação assumida nos termos de um acordo internacional. E sta regra deve ser interpretada conjuntamente com o artigo 46 da Convenção de Viena, que dispõe no sentido de que um E stado não poderá al egar a violação de um dispositivo legal doméstico como vício de consentimento na assinatura de um tratado internacional, a menos que tal violação seja manifesta e pertinente à regra de importância fundamental. O s EU A até hoje não ratificaram a C onvenção de Viena, embora sejam signatários dela.

C omo vimos, a Convenção de V iena pretende estabelecer uma certa disciplina legal, bem como juridicidade, aos tratados internacionais, para limitar 0 abuso de tais instrumentos pelas potências hegemônicas em detrimento dos demais Estados. As formas de abuso de tratados internacionais são abundantes e a 
história tem um triste legado de infames exemplos. U ma destas formas é o estabelecimento de um acordo internacional de maneira que seus termos sejam exeqüíveis contra um Estado, mas que a recíproca não seja verdadeira.

$\mathrm{N}$ a hierarquia das normas no direito constitucional doméstico dosEU A, há dois patamares distintos para a classificação dos tratados internacionais: o primeiro deles diz respeito à sua origem, C ongresso ou Poder Executivo. N este caso, as convenções aprovadas pelo Congresso são denominadas "tratados" 10 e têm a mesma hierarquia da legislação federal. Aquelas convenções de origem apenas do Poder Executivo são denominadas de "acordo executivo presidencial" ${ }^{11}$ e estão subordinadas à legislação federal.

O segundo patamar diz respeito à exeqüibilidade direta ou indireta do acordo. N este particular, os tratados internacionais são divididos, de um lado, em acordos auto-exeqüíveis, que não necessitam de legislação doméstica que os implementem e, de outro, em acordos não automaticamente exeqüíveis, que necessitam de implementação legislativa. U m acordo internacional dos EU A, de acordo com seu direito interno, não é automaticamente exeqüível, quando:

i) o tratado manifesta uma intenção de não se tornar eficaz como direito interno sem legislação que o implemente;

ii) o Senado ou o Congresso, ao dar autorização a um tratado, requerer legislação que o implemente; ou

iii) a implementação legislativa for necessária por força de dispositivo ou jurisprudência constitucional ${ }^{12}$.

De qualquer maneira, o Poder J udiciário dos EU A não reconhece os acordos não exeqüíveis ${ }^{13}$. Assim, de um modo geral, todos os tratados internacionais assinados pelos EU A nos últimos 25 anos têm necessitado de implementação legislativa interna, devido a pelo menos um dos requisitos acima, mas freqüentemente por todos eles. O s acordos internacionais de comércio não fogem, é claro, à regra. Ao contrário, já que numerosos e ponderáveis interesses privados e públicos podem neles ser substancialmente afetados, quer de forma positiva, quer de maneira adversa.

U m exemplo dramático de tal situação pode ser encontrado com relação ao Acordo de Estabelecimento da O rganização M undial do Comércio (OMC), doravante denominado simplesmente Acordo da O M C. N este caso, os Estados signatários comprometeram-se a aceitar a totalidade dos tratados objeto do Acordo da O M C, bem como obrigaram-se a assegurar a conformidade de suas leis, regulamentos e procedimentos administrativos com seus respectivos dispositivos ${ }^{14}$. $\mathrm{N}$ enhuma reserva foi autorizada com respeito a qualquer dispositivo do Acordo da OM C. Reservas com relação a qualquer dos dispositivos de quaisquer dos tratados objeto do Acordo da O M C somente poderiam ser feitas se expressamente autorizadas pelos seus termos ${ }^{15}$. 
N o entanto, a apósita legislação de implementação interna nos EU A a respeito do Acordo da OMC, e de seus tratados anexos, estabelece que "nenhum dispositivo de qualquer dos Acordos da Rodada U ruguai, nem a aplicação de qualquer tal dispositivo a qualquer pessoa ou circunstância, que seja inconsistente com qualquer lei dos EU A, deverá produzir efeitos ${ }^{16}$." De maneira idêntica, a legislação federal interna de implementação do $\mathrm{N}$ afta nos EU A dispõe que "nenhum dispositivo do Acordo nem a aplicação de tal dispositivo a qualquer pessoa ou circunstância que seja inconsistente com qualquer lei dos EU A deverá produzir efeitos ${ }^{17 "}$.

D e uma perspectiva de política externa, esta subordinação do direito internacional à lei interna americana foi explicada por Claude E. Barsfield da seguinte maneira

ironicamente, até recentemente, os EU A seguiram uma política ad hoc de aplicar efeito direto a alguns tratados e de recusar a aplicá-la a outros. C omentários oficiais sobre direito doméstico e internacional sugeriram que, na ausência de um pedido do Congresso ou do Presidente para legislação de implementação, um tratado seria auto exeqüível e derrogaria a lei interna existente ${ }^{18}$.

Todavia, continua o mesmo autor,

desde o fim dos anos 80, um intervencionismo crescente do Congresso mudou a situação de maneira substancial. Em quatro grandes acordos de comércio - o EU A / I srael; o EU A / C anadá, o do N afta e o A cordo da O M C o consentimento do Congresso foi outorgado somente com a condição de uma denegação explícita de efeito direto ou auto-exeqüibilidade ${ }^{19}$.

Por outro lado, pelo prisma do direito internacional, estes dispositivos inseridos na legislação doméstica de implementação nos EU A, inclusive do Acordo da O M C e daquele do N afta são flagrantemente ilegais. I sto ocorre não somente porque tais dispositivos estão em clara violação de normas específicas daqueles tratados, mas também porque violam igualmente as provisões diversas da Convenção de Viena supra mencionadas. A natureza de tal violação é tanto mais grave que a Corte Internacional de Justiça $(\mathrm{CIJ})$ já decidiu que "se uma parte objeta a uma reserva porque a considera incompatível com o objeto e propósito de um tratado, aquela parte poderá considerar o Estado formulador da reserva como não-parte" 20 .

A conseqüência de ordem pragmática desta situação é que os EU A colocam de facto seu ordenamento jurídico interno acima dos tratados internacionais. Tal audacioso posicionamento significa que um determinado dispositivo de um dado acordo internacional obrigará todas as suas partes, mas não necessariamente os EU A e seus nacionais. I sto ocorre porque nos ordenamentos jurídicos de quase todos os 146 membros da OM C, os tratados internacionais situam-se acima da legislação doméstica ou direito interno, na hierarquia das normas. As- 
sim, se um dispositivo do Acordo da OMC, do Nafta ou mesmo da Alca for contrário a uma dada lei interna dos EU A de flagrante ilegalidade, como é o caso da Seção 30121, por exemplo, isto significa que prevalecerá a Seção 301 sobre 0 acordo internacional. Por outro lado, a mesma norma inexeqüível contra os EU A e seus nacionais será plenamente exeqüível contra os demais E stados e seus nacionais, com relação a um dispositivo semelhante de direito interno.

D a mesma forma, a legislação interna de imigração dos EU A, que representa uma formidável barreira horizontal de acesso a eventuais prestadores de serviços dos países signatários de uma possível Alca, prevalecerá, como prevalece no âmbito do $\mathrm{N}$ afta, sobre todos e quaisquer promessas e/ ou dispositivos do respectivo acordo da Alca, com a sua denegação inexorável na realidade prática, da mesma forma do ocorrido no âmbito da chamada "liberalização" de serviços promovida no âmbito do Acordo Geral de Comércio em Serviços (GATS), havida como resultado da Rodada U ruguai do Acordo Geral de Tarifas e Comércio (GATT).

No caso da Alca, a legislação interna dos EU A sobre a autorização dada pelo Congresso ao Poder Executivo daquele país para a negociação de tratados internacionais, conhecida informal e tradicional mente como via rápida, Fast-track A ct, denegou que o eventual acordo da Alca tenha efeito direto ou auto-exeqüível, necessitando portanto de aprovação legislativa. D e fato, chamada lei de promoção comercial ${ }^{22}$ dos EU A, que trata inclusive das negociações da Alca, determina especificamente que o eventual acordo respectivo seja apresentado para ratificação e legislação específica de implementação pelo Congresso daquele país ${ }^{23}$.

Assim, muito embora a minuta do acordo da Alca ${ }^{24}$ estabeleça o princípio da boa fé25, proíba explicitamente a formulação de reservas ${ }^{26}$, e determine que haja a consistência das leis internas com os dispositivos do tratado ${ }^{27}$, a autorização limitada recebida pelos negociadores estadunidenses, bem como a específica necessidade de legislação de implementação, indica que provavelmente ocorrerá, na eventual assinatura do respectivo pacto comercial, o mesmo problema de implementação havido com os outros acordos mencionados anteriormente. I sto porque todos os outros acordos têm dispositivos idênticos ou assemelhados. 0 objetivo doS EUA com tais normas é assegurar sua observância absoluta apenas pelos outros países, mas não por si mesma. Desta maneira, o direito interno estadunidense será resguardado e colocado acima das normas da Alca.

O utra idiossincrasia faz com que a questão da hierarquia das normas tornese ainda mais preocupante com relação à iniciativa da Alca. D e fato, a minuta do acordo da Alca dispõe que, na eventualidade de um conflito entre os dispositivos deste e os do A cordo da O M C , prevalecerão as normas do acordo da Alca ${ }^{28}$, num dispositivo de muito questionável legalidade. Esta situação, se prevalecer, acarretará uma inversão radical na hierarquia das normas, no sentido de que, nas amplas matérias tratadas no âmbito do acordo da Alca, a hierarquia superior será das leis dosEU A, situando-se num segundo patamar as normas da Alca, deixando-se 
para o posto mais baixo as regras multilaterais da OMC. Assim, conforme contemplado pelo acordo da Alca, a hierarquia das normas para aplicação interna seria a seguinte:

$\mathrm{H}$ ierarquia maior

$\mathrm{H}$ ierarquia menor

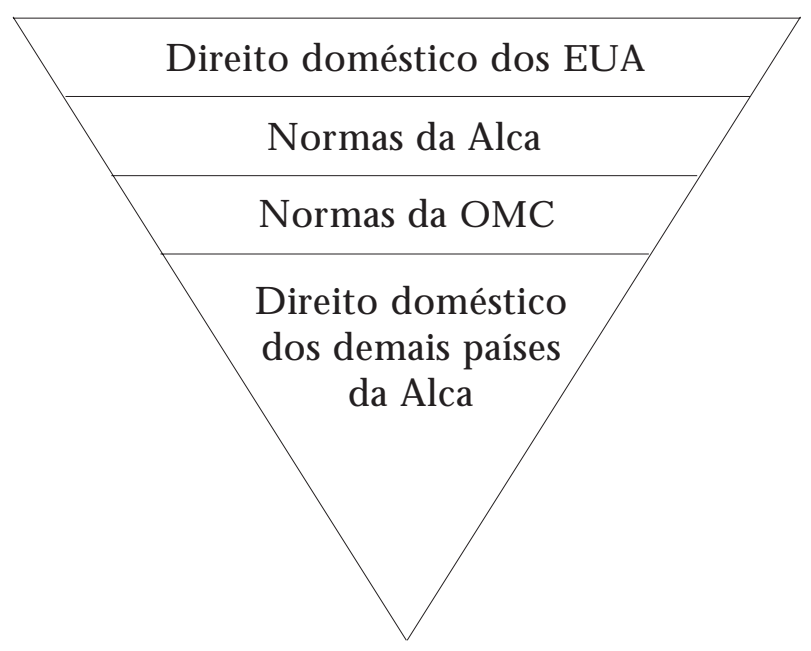

Todavia, a correta estrutura jurídica em ordem de importância, face ao direito internacional e aos mais básicos princípios de eqüidade, para aplicação interna, seria:

$\mathrm{H}$ ierarquia maior

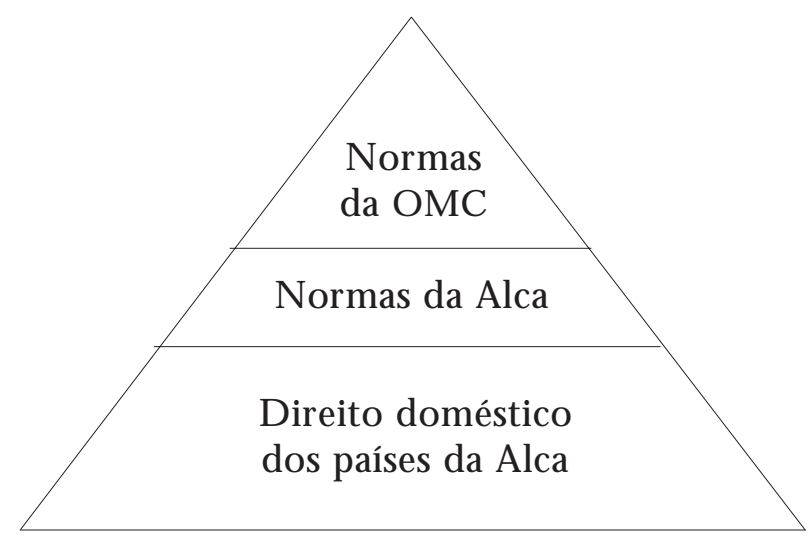

\section{A natureza ilícita}

\section{da oferta discriminatória dos E U A no âmbito da Alca}

O anúncio das linhas gerais da proposta dos EU A para a Alca, feita no dia 11 de fevereiro de 2003, chamou a atenção não somente pelo já previsível caráter 
acanhado, singularmente cosmético e anódino, como também pelo tratamento discriminatório dado às possíveis partes do futuro pacto comercial por aquele país ${ }^{29}$.

O ra, o fundamento básico e arcabouço legal do regime jurídico do comércio internacional é justamente o chamado princípio da não discriminação, consagrado no Artigo 10 do tratado do GATT de 1947, ainda em vigor, pela chamada cláusula da nação mais favorecida, segundo a qual qualquer vantagem, favor, privilégio ou imunidade concedida por um país signatário do tratado, a qualquer produto de um país nas mesmas condições, será imediata e incondicionalmente estendida a todos os demais signatários. Com a criação da O M C em 1995, a norma passou a ser aplicada aos hoje 146 Estados-membros da organização.

Trata-se, como visto, de um princípio absoluto, "incondicional", que não autoriza exceções não permitidas pelo próprio tratado. 0 artigo 24 do GATT 1947 permite apenas exceções no tocante às zonas de livre comércio e uniões alfandegárias, naquilo em que o seu regime pode ser mais benéfico do que aquele outorgado aos demais parceiros comerciais. A justificativa do dispositivo é o reconhecimento de que a liberalização regional é um passo na liberalização global dos mercados, que é o objetivo último do sistema multilateral de comércio. Assim, a discriminação trazida pela liberalização regional traria, numa segunda fase, um benefício global de longo prazo.

D e qualquer forma, o parágrafo 5b do artigo 24 do GATT 1947 determina que as tarifas regionais de uma dada área de livre comércio não poderão ser maiores ou mais restritivas do que aquelas existentes nos respectivos territórios, antes de sua formação. 0 tratado não dispõe se tais restrições devam ser interpretadas em critérios absolutos ou relativos. D esta maneira, a ordem jurídica multilateral da OM C permite, excepcionalmente, nos casos de pactos regionais de livre comércio, como é o caso da iniciativa da Alca, a discriminação exógena, ou seja o tratamento diferenciado aos não signatários.

Todavia, esta autorização legal do GATT 1947 não contempla a modalidade, introduzida pelos EU A pela primeira vez na história dos pactos regionais de comércio, da discriminação endógena, em contundente violação dos dispositivos já mencionados. D e fato, a oferta agrícola, por exemplo, dá tratamento tarifário isento a $85 \%$ das exportações do M ercado Comum do Caribe (Caricom); 64\% daquelas dos países da A mérica C entral; $68 \%$ das procedentes dos países do Pacto Andino; e 50\%àquelas oriundas dos países do M ercado Comum do Sul (M ercosul).

Por sua vez, a oferta de bens industriais e de consumo feita pelos EU A dá uma isenção tarifária a $91 \%$ dos produtos do Caricom, $66 \%$ dos produtos da América Central; $61 \%$ dos produtos do Pacto Andino; e $58 \%$ dos produtos do M ercosul. Resta ainda saber se essa discriminação não será agravada, por ocasião da oferta final dos EU A, pela tarificação diferenciada de bens e produtos, na exata medida da competitividade de cada país, de tal maneira que o país mais competitivo tenha tarifas mais elevadas e o menos competitivo, tarifas mais baixas. 
Como bem observado por Rubens Ricupero,

por esse insólito processo, fabrica-se uma espécie de Frankenstein dos acordos de livre comércio, um monstro com um mínimo de quatro velocidades distintas, que podem chegar a mais, desde que se computem os regimes diversos do $\mathrm{N}$ afta, para o Canadá e o M éxico, bem como o do acordo com 0 Chile $^{30}[\ldots]$, volta-se ao formato mais nocivo das negociações, o do chamado sistema do "eixo e raios", no qual os EU A, o eixo, negociariam, um a um, com cada país ou grupo de países, os raios, dividindo-os, enfraquecendo-os, de modo a poder extrair o máximo de cada um ${ }^{31}$.

D e qualquer maneira, o uso de percentuais de liberalização é um argumento tradicional e falacioso dos negociadores estadunidenses. De um modo geral, as tarifas nos EU A já são razoavelmente baixas, situando-se num patamar médio de aproximadamente 3\%. Assim, uma redução de $91 \%$ de uma tarifa de $1 \%$ não representa muito em termos de maior concessão de acesso a mercado. C omo resultado, estas concessões percentuais muito pouco significam na prática em termos de ganhos de competitividade para os agentes econômicos dos países signatários de pactos comerciais regionais com os EU A.

A áreas em que uma liberalização poderia fazer significativa diferença de competitividade a favor de maior competitividade dos parceiros comerciais nos mercados dos EU A são, justamente, aquelas problemáticas. Assim, dificuldades comerciais e problemas normalmente existentes com os EU A situam-se, em primeiro lugar, nos picos tarifários, que são sempre mantidos por aquele país, quer em negociações multilaterais, quer regionais. Em segundo lugar, são encontradiços nas barreiras horizontais, como no caso da movimentação de prestadores de serviços. Em terceiro lugar, existem nos subsídios que, apenas no setor agrícola, comprometeram a existência de uma economia de mercado na área. E m quarto lugar, encontram-se no arsenal unilateral, como na já mencionada Seção 301, e na legislação antidumping. Por último, deparamo-nos com a freqüente inobservância do direito internacional por órgãos da administração direta, indireta e do Poder Judiciário dos EU A.

\section{0 anacrônico sistema de arbitragem porposto para a Alca}

O sistema de arbitragem proposto para a Alca foi substancialmente fundado naquele em existência na O M C desde 1995, com desastrosos resultados para a prestação jurisdicional do direito do comércio internacional, bem como para os países em desenvolvimento, suas maiores vítimas² . Já em 1998, quando deveria ter havido uma revisão do procedimento, já eram evidentes os vícios sistêmicos e fal has operacionais do sistema de resolução de disputas da O M C, em sua grande maioria ${ }^{33}$. N os países em desenvolvimento, já havia na ocasião um consenso de que o sistema de resolução de disputas da o m c era desastroso para os seus interesses, excepcionando-se alguns tanto disparatados como isolados comentários, como aqueles de Celso Lafer, que o chamou de uma "success story" ${ }^{44}$ ( (ic). 
A verdade é que, por ocasião da Rodada Doha da OMC, muitos países apresentaram propostas para a reforma do sistema de resolução de disputas da O M C , incluindo a Austrália, o Brasil, o C anadá, o C hile, a China, a C oréia do Sul, o Equador, os EU A, a Í ndia, Taiwan, a Tailândia, a U nião Européia, e dois grupos de países, um da África, e outro de países menos desenvolvidos. As propostas de reforma apresentadas compreendem modificações substanciais a todos os 24 artigos e quatro anexos ao Entendimento sobre Resolução de D isputas (ERD) da O M C ! A reforma tornou-se a reconstrução de um sistema profundo e inexoravelmente comprometido por seus muitos vícios e defeitos, que causaram sua completa desmoralização.

As áreas em que reformas foram propostas para o ERD são basicamente sete:

i) consultas;

ii) formação e regras processuais dos painéis de primeira instância;

iii) regras processuais de segunda instância;

iv) execução;

v) regras especiais para países em desenvolvimento; e

vi) novo tratamento para terceiros e amicuscuriae.

Pois bem, o sistema de arbitragem proposto para a A lca incorpora praticamente a totalidade dos vícios daquele da O M C , sem levar em consideração o processo de reforma presentemente em andamento. $M$ ais ainda, conforme já mencionado ut supra, a minuta do acordo da $\mathrm{Alca}^{35}$ coloca este acima daquele da O M C. Redigido em linguagem não jurídica, o que também é um grave problema do ERD, o capítulo de arbitragem do acordo da Alca (capítulo de arbitragem) dá como jurisdição, denominada "escopo de aplicação" ${ }^{36}$ (sic), a resolução de todas disputas entre as partes com relação à interpretação, aplicação (sic) ou não observância do acordo da Alca. 0 direito de ação é restrito aos Estados signatários ${ }^{37}$, sendo expressamente vedado o direito da ação a pessoas físicas ou jurídicas de direito privado ${ }^{38}$.

0 artigo 4 do capítulo de arbitragem manda aplicar às disputas os princípios de direito internacional, bem como aqueles de boa fé, confidencialidade, celeridade, economia processual, acesso efetivo, tratamento especial e diferencial, bem como um equilíbrio entre direitos e obrigações das partes. 0 que vem a ser objeto do "tratamento diferencial" a países em desenvolvimento ${ }^{39}$ é definido da seguinte forma "medidas como" ( sic) maiores prazos; direito a assistência jurídica; e garantia de poder comunicar em quaisquer das línguas da Alca (sic). Por sua vez, a confidencialidade é assegurada a todos os documentos apresentados pelas partes, à exceção do laudo final e das notificações efetuadas ${ }^{40}$ ao Secretariado. O s outros princípios não se encontram definidos no texto do capítulo de arbitragem, o que poderá dar ensejo a grandes confusões e injustiças. Por exemplo, na O M C , a questão da "economia processual" é altamente controversa por ter sido tratada na prática como déni de justice, ou omissão de julgar um dos pontos apresentados por uma das partes, quase sempre um país em desenvolvimento. 
O capítulo de arbitragem cria o fôro privilegiado da Alca para todas as questões atinentes ao acordo da Alca. Q uanto às demais, poderão ser submetidas tanto ao sistema de resolução de disputas da O M C , quanto ao da Alca, à exclusão do outro ${ }^{41}$. Estes dispositivos deverão criar enorme controvérsia, tendo em vista que a maior parte das matérias substantivas, senão a totalidade, deverá ser de jurisdição de ambos os sistemas, e que haverá uma discrepância importante na regulamentação processualística de ambos, o que implicará certamente numa relação hierárquica de credibilidade dentre eles.

$\mathrm{O}$ sistema de arbitragem da Alca, cria, à semelhança daquele presentemente existente na O M C , um sistema confidencial de consultas ${ }^{42}$. É na área de consultas que se dá a maior parte das derrotas dos países em desenvolvimento no âmbito da O M C. O seu mecanismo não transparente tem implicado, na O M C , a falta de controle democrático dos atos praticados pelos agentes governamentais dos países em desenvolvimento ${ }^{43}$, devido ao sigilo nas concessões feitas. É de se notar que a proposta feita pela Í ndia na reforma do sistema de consultas da O M C , de dar maior consideração aos interesses dos países em desenvolvimento, não tenha sido levada em consideração no âmbito da Alca.

Similarmente ao que existe hoje na O M C , o capítulo de arbitragem da Alca cria um painel de primeira instância e outro de apelação ${ }^{44}$. 0 primeiro, seguindo o vício consagrado na $\mathrm{OMC}$, terá caráter não permanente e será nomeado pelo Secretariado, que na O M C é controlado pelas potências hegemônicas, por meio da indicação dos postos-chave na D ivisão J urídica. Como na O M C, haverá uma lista de árbitros de primeira instância ${ }^{45}$, mas naquela organização estes normalmente não são nomeados, em detrimento dos amigos dos componentes da D ivisão J urídica do Secretariado, com os previsíveis resultados. No âmbito da reforma do sistema de resolução de disputas da O M C, muitas propostas foram apresentadas para a criação de um corpo permanente de árbitros de primeira instância, de forma a combater a imoralidade que se instalou em Genebra.

I gualmente ao que ocorre hoje no âmbito da O M C , o grau de apelação no sistema de arbitragem da Alca terá um corpo permanente de sete árbitros, indicados por um mandato de quatro anos, prorrogável por igual período ${ }^{46}$. A jurisdição de segunda instância será sobre questões de direito, apenas ${ }^{47}$. 0 painel de segunda instância decidirá por maioria de votos ${ }^{48}$. 0 painel do grau de apelação, da mesma maneira que ocorre na OM C e que muitos problemas têm causado, não terá poderes para remeter os autos para o painel de primeira instância, convertendo o julgamento em diligência, com o objetivo de complementar ou esclarecer questão de fato. I sto é uma falha adicional do sistema não permanente de árbitros de primeira instância, já que quando o caso sobe para o grau de apelação, o painel original de árbitros não mais existirá.

As regras processuais do sistema de arbitragem da Alca, formuladas com base naquelas já existentes na O M C, são igualmente muito fal has. 0 sistema de arbitragem da Alca admite o litisconsórcio ativo ${ }^{49}$, mas é silente quanto ao litiscon- 
sórcio passivo. Segundo o artigo 19 do capítulo de arbitragem, "quando uma parte não é uma parte na disputa, ela poderá participar como terceira parte" (sंc). Este é o mesmo mecanismo existente no ERD, que tem sido amplamente criticado no âmbito da OMC.

D a mesma maneira, a questão das regras de prova e evidência, que é absolutamente deficiente na O M C , foi copiada pela Alca ${ }^{50}$. H á também na proposta da Alca um anexo com regras de procedimento, absolutamente inadequadas, mas com alguns poucos progressos com relação às da $O M \mathrm{M}^{51}$, como por exemplo um tratamento da questão do "ônus da prova" , objeto de bizantinos debates no sistema multilateral. Por outro lado, numa das poucas inovações com relação ao sistema da O M C, foi admitido o instituto das medidas cautelares, denominadas "medidas provisórias" no âmbito da arbitragem da Alca52. Como veremos mais adiante, tendo em vista as dificuldades no sistema de sanções como presentemente estruturado no sistema de arbitragem da Alca, formulado com base naquele da O M C , é difícil vislumbrar como poderão tornar-se exeqüíveis as "medidas provisórias".

O sistema de arbitragem da Alca, à semelhança do seu modelo da O M C, peca igualmente por muitas omissões processuais de fundamental importância para qualquer sistema jurisdicional. Assim, o sistema não possui qualquer instrumento processual para o tratamento de preliminares como, inter alia, carência de ação, ilegitimidade de parte, incompetência de fôro ou conflito de tratados. A experiência da O M C demonstrou que estas omissões trazem um alto custo para os países em desenvolvimento, no que toca à derrogação de direitos reconhecidos por outros tratados. D a mesma forma, o sistema de arbitragem da Alca, à semel hança do tratamento dispensado na O M C , não admite o instituto da reconvenção, o que pode causar a existência de dois casos conexos, com painéis diversos, com possíveis termos de referência semelhantes e com resultados desencontrados.

À semelhança do que ocorre na O M C, o sistema de arbitragem da Alca não enseja laudos ou decisões auto-exeqüíveis. Esta falha gerou graves problemas no âmbito multilateral, onde a maioria das decisões tem problemas de execução ou implementação. Assim, por ocasião de uma decisão, a parte vencida terá como opção a oportunidade de remover a medida causadora da divergência ${ }^{53}$. C aso, todavia, a parte vencida recuse-se a tanto, não haverá nenhuma execução específica do laudo. Como alternativa, caberá então à parte vencedora da disputa entrar em entendimentos com a parte vencida para tentar acordar em compensações, isto é, a revogação de vantagens tarifárias da primeira para com a segunda, com o objetivo de compensar as perdas sofridas pela primeira como resultado das medidas ilegais da segunda. C aso não haja entendimentos entre as duas partes, caberá à arbitragem da Alca determinar a natureza e o montante da revogação das vantagens tarifárias, o que é chamado de retaliação ${ }^{54}$.

Esta sistemática importada da OM C tem o gravíssimo inconveniente de penalizar a corrente saudável de comércio entre os dois países envolvidos numa 
dada disputa, além de não ter execução específica na remoção da medida julgada ilegal ou inconsistente com a ordem jurídica de regência da atividade afetada. $\mathrm{N} o$ âmbito da Rodada Doha da OM C, muitas são as propostas para a reforma do sistema de sanções, prevendo-se uma árdua batalha antes que um consenso seja obtido. Qualquer progresso feito no âmbito multilateral fará o seu sistema de resolução de disputas certamente mais eficaz do que este proposto para a Alca.

D e resto, vale ainda observar que a formatação do proposto sistema de arbitragem da Alca parece, pela técnica utilizada, ter sido quase, senão totalmente, de responsabilidade e iniciativa dosE $\mathrm{A}$, os grandes inspiradores e beneficiários do ERD da O M C. I sso ocorre tanto em questões substantivas, como também na técnica jurídica empregada. M esmo onde há divergências entre os modelos, as soluções oferecidas são normalmente aquelas propostas, patrocinadas e/ ou defendidas pelos EU A no regime multilateral.

\section{Conclusões}

C omo resultado desta análise, limitada a alguns aspectos legais da iniciativa da Alca, examinamos como nos EU A, hoje, a lei interna prevalece sobre os tratados internacionais de comércio na hierarquia das normas no direito constitucional daquele país. Como conseqüência, vimos que muitos dispositivos dos tratados internacionais não revogam a lei doméstica e, por conseguinte, não beneficiam os nacionais dos países que entram em acordos comerciais com aquele país, notadamente os de caráter regional, onde as relações de poder fazem-se sentir de maneira mais contundente. Examinamos ainda a questão preocupante da tentativa de derrogação da ordem jurídica multilateral do comércio, onde há melhores condições de resistência ao arbítrio, pelo pacto regional da Alca, onde as possibilidades de autodefesa serão muito menores.

Por outro lado, vislumbramos como a oferta discriminatória feita pelosEU A no âmbito da Alca é ilegal do ponto de vista jurídico e insubsistente do ponto de vista tarifário.

E ainda, por último, detivemo-nos na anacrônica proposta de arbitragem da Alca, baseada num infame modelo que, presentemente, está sendo objeto de reconstrução e que trouxe enormes dificuldades e injustiças para os países em desenvolvimento no âmbito da O M C. A plicado o sistema à Alca, nos moldes que estão para ser superados pela reforma do ERD e ainda colocado, como está, acima da ordem multilateral da OM C, teremos o infausto resultado de que nossas disputas com osEU A serão sempre apresentadas ao modelo que nos será mais adverso: aquele da Alca.

Assim, ainda que os argumentos macroeconômicos fossem favoráveis ao ingresso do Brasil na Alca (e não o são), apenas a situação jurídica seria decisiva a absolutamente desaconselhar tão temerária aventura. 
N otas

1 Firmado entre osEU A, Canadá e M éxico em 1992, tendo entrado em vigor em 1o de janeiro de 1994.

2 Para a agenda negociadora dos EU A no âmbito da Alca, ver D urval de N oronha Goyos J r., "Ensaios de D ireito I nternacional", O bservador L egal, São Paulo, 2000, p. 259.

3 Para uma análise ampla do tema de serviços na Alca, ver D urval de $\mathrm{N}$ oronha G oyos J r., "A Serviço de Q uem?" CadernosD iplô- LeM ondeD iplomatique, n. 4, 2002, pp. 26 e ss.

4 "M exico's President Signs Farm Accord, Seeks N afta Side Pacts on Corn, Beans", International Trade Reporter, vol. 20, n. 18, 10 de maio, 2003, pp. 762 e 763.

5 D urval de N oronha Goyos J r., "O M ercosul, a Área de Livre Comércio das Américas e a O rganização M undial do Comércio", C rítica J urídica, Curitiba, n. 20, 2002, pp. 177.

6 Ver, por exemplo, Samuel Pinheiro Guimarães, "A Alca e o fim do M ercosul", em A lca e M ercosul: R iscos eO portunidades para o Brasil, I PRI, Brasília, 1999, p. 290 e ss. Ver também, Paulo N ogueira Batista J r., "A Alca e o Brasil", março de 2003, a ser publicado na R evista deEstudos A vançadosda U SP, n. 38, jul.-ago. 2003, São Paulo.

7 Ver por exemplo, Jaime César Lipovetsky e D aniel Andrés Lipovetsky, “EI D erecho del Trabajo en los Tiempos lel ALCA: Entrela G lobalización y los B loques R egionales", E ditorial D istal, Buenos Aires, 2002.

8 D atada de 23 de maio de 1969, tendo entrado em vigor em 27 de janeiro de 1980.

9 Durval de Noronha Goyos Jr., "Reflections on Certain U S Law Specificities that Constitute $O$ bstacles to the Free Trade Area of the Americas: A Brazilian Perspective", Thel nter-A merican Law R eview, U niversity of M iami, vol. 28, n. 3, 1997, pp. 543-563.

10 Em inglês, "treaties".

$11 \mathrm{Em}$ inglês, "presidential executiveagreements".

12 Restatement (Third) of the Foreign Relations $L$ aw of the $U$ nited States (1987).

13 D urval de N oronha Goyos J r., "Reflections on Certain...", op. cit.

14 Artigo XVI, 4, do Acordo da OMC.

15 Artigo XVI, 5, do Acordo da OMC.

16 Secção 102 (a), 19 U .S.C., parágrafo 3512 (a). Tradução do autor.

1719 U .S.C., parágrafo 3312. Tradução do autor.

18Claude E. Barsfield, "F ree Trade, Sovereignty, D emocracy - The Future of the World Trade O rganization", TheA IE Press, Washington, 2001, p. 133. Tradução do autor. 19 Claude E. Barsfield, op. cit.

200 pinião sobre a Convenção sobre G enocídio de 1948. ICJ Reports (1951). Tradução do autor.

21 Seção 301 do Ato de Comércio e Tarifas de 1974, que autoriza o Representante Comercial dosEU A a investigar e sancionar países com práticas de comércio consideradas "desleais".

22 Trade Promotion Authority Act, ou Public Law 107-210, de 6 de agosto de 2002. 
23 Public Law 107-210, seção 2103, 3, B.

$24 \mathrm{M}$ inuta de 1 o de novembro de 2002, na língua inglesa. Todas e quaisquer traduções para o português são de responsabilidade do autor.

25 Artigo 3 (h).

26 Artigo 24.

27 Artigo 4.2.

28 Artigo 4.4.

29 U ma versão resumida deste capítulo foi publicada por D urval de N oronha G oyos J r. em http:/ / aefinanceiro.com.br, com o título "A N atureza l lícita da O ferta dos EU A no Âmbito da Alca", em 14 de fevereiro de 2003.

30 Rubens Ricupero, "Alca de geometria variável", Folha de S.Paulo, 27 de abril de 2003, p. B2.

31 I dem.

32 Ver D urval de N oronha Goyos J r., EnsaiosdeD ireito I nternaci onal, O bservador Legal, São Paulo/ M iami, 2000, p. 59.

33 D urval de N oronha Goyos J r., "O sistema de resolução de disputas da O rganização M undial do Comércio e os países em desenvolvimento", Galileu, R evista de Economia e Direito, 2001, vol. VI, n. 2, Lisboa.

34C elso Lafer, "A OM C e a Regulamentação do Comércio Internacional: uma visão brasileira", Livraria do Advogado, Porto Alegre, 1998, p. 151.

35 Artigo 4.4. Ver também nota 29 supra.

36 Artigo 2 do capítulo de arbitragem.

37 Artigo 4 do capítulo de arbitragem.

38 Artigo 44 do capítulo de arbitragem.

39 Artigo 5 do capítulo de arbitragem.

40 Artigo 39 do capítulo de arbitragem.

41 Artigo 6 do capítulo de arbitragem.

42 Artigo 7 do capítulo de arbitragem.

430 s países desenvolvidos têm normalmente meios mais eficazes de controle.

44 Artigo 11 do capítulo de arbitragem.

45 Artigos 12 e 13 do capítulo de arbitragem.

46 Artigos 29 e 30 do capítulo de arbitragem.

47 Artigo 32 do capítulo de arbitragem.

48 Artigo 32 do capítulo de arbitragem.

49 Artigo 17 do capítulo de arbitragem.

50 Artigo 20 do capítulo de arbitragem.

51 Artigo 16 do capítulo de arbitragem e Anexo XX.

52 Artigo 21 do capítulo de arbitragem.

53 Artigo 27 do capítulo de arbitragem.

54 Artigo 35 do capítulo de arbitragem. 
R esumo - Con Cebid a pelos Estados U nidos da América (EU A), a iniciativa da Área de Livre Comércio das Américas (Alca), pela forma jurídica apresentada, constitui um sistema anacrônico e discriminatório, por assegurar a descabida manutenção da primazia da lei interna norte-americana sobre os tratados internacionais, por estabelecer ofertas discriminatórias, principalmente sob a ótica tarifária; e por co-optar o infame modelo de arbitragem da O rganização M undial do Comércio (O M C). D a forma como está estruturada, ainda que fossem favoráveis os argumentos macroeconômicos ao ingresso do Brasil naAlca, apenas a situação jurídica desencorajaria qualquer tipo de entendimento.

A BSTR A CT - THE FRAM EWORK of the initiative of the Free Trade Area of the Americas (FTAA), as conceived by the $U$ nited States of America (U SA) and presented to the other countries of the hemisphere, is, from a legal perspective, both discriminatory and anachronic. This is so because the adopted structure allows for the superiority of U S internal laws over treaty obligations; because the offers made by the USA are discriminatory; and because thedispute resolution system contemplated for the FTAA is based on the World Trade O rganization (WTO) model, which has fallen into disrepute as a result of its manipulation in detriment of developing countries and is now undergoing a thorough process of revision within the ambit of the Doha Round.

D urval de N or onha Goyos] r. é advogado inscrito no Brasil, Inglaterra e G ales e Portugal. Sócio principal de N oronha-Advogados. Árbitro do GATT e da OM C. Professor de pós-graduação de Direito do Comércio Internacional.

Texto recebido e aceito para publicação em 21 de maio de 2003. 